\title{
The Calibre of Personnel Influence of Management's Compliance to Internal Control Systems in Organizations and Institutions
}

\author{
JOHN Awuni, PHILIP Baidoo*, GEOFFREY Mensah and ABRAHAM Attoh \\ ogahawuni@gmail.com,mypennich@yahoo.com,geomens4@gmail.com and attohbarclay@yahoo.com \\ College of Technology Education Kumasi, University of Education, Winneba, Ghana
}

DOI: 10.29322/IJSRP.10.07.2020.p10373

http://dx.doi.org/10.29322/IJSRP.10.07.2020.p10373

\begin{abstract}
Internal control systems in every institution in the world, determines ways of evaluating staff of the institutions. Though the strategic may differ, purposes are virtually the same. However, this study investigated the Calibre of Personnel Influence of Management's Compliance to Internal Controls at the level of Organizations and Institutions. The research design employed was characterized and analyzed the purpose of the study. Purposive sampling techniques were used to select the respondents. The sample size for the study was fifty (50) participants and six (6) internal control units of management members, Junior and senior staff, respectively. Questionnaire and interview guide were used to collect data from the respondents which was analyzed to generate frequencies and percentages with the help of Microsoft Excel. The study resulted that the evaluations influence of the internal control systems on managerial tools that can be used to impact the attitudes of employees in institutions and organizations revealed that various constituents of internal control systems in the institutions and possible strategies and mechanism were placed. However, Management area involving their subordinates had a lesser attention insert and internal control systems were not motivating enough. Therefore, process of evaluation was in-effective, which had embarked influence on the Institution, and their subordinates has a lesser attention insert.
\end{abstract}

Key Words: Internal control; Personnel Influence; Organizations and Institutions; investigation.

\section{Introduction}

Internal control (IC) systems has been the subject of a series of inquiries today. However, some organization in both government and private sector, legislators and regulators, gave internal control significant attention as a result of Watergate revelation of illegal domestic political contributions and questionable activities. [1]The nature of the organization and other related factors and conditions in the environment will show the type of IC system to be adopted. However in regards to financial control systems, there were incidents of illicit payment to foreign government officials' by united State (U.S.) Companies. Subsequently, the Foreign corruption practices Act was enacted, followed by a number of private and public sector studies, proposals and recommendations on internal controls . [2] A number of studies have been conducted on IC. One of such studies was conducted by auditing standard and auditor's performance [3]. The Commission examined the causes of fraudulent financial reporting and provided recommendations to reduce its incidence. One of its recommendations was that organisations should work together to develop a common definition for internal controls and to provide guidance on studying the effectiveness of, and improving, internal controls. This system plays an important role in both internal and external auditing practices of checks and balances [4]. Internal auditing practices appraise the effectiveness of internal control systems. Internal control ensures that opportunities for fraud or malfeasance are minimized. It enables Management to carry out the business of the company in an orderly and efficient manner. The system ensures that management policies are adhered to, assets are safeqaurded, and records of the company's activities are both complete and accurate. [5] Lack of proper IC in public and private Universities has accounted for a number of instances of fraudulent financial reporting and This publication is licensed under Creative Commons Attribution CC BY. 
irregularities in management policies. However, the effectiveness of IC policies and procedures cannot rise above the integrity and ethical values of people who create, administer, and monitor them. Integrity and ethical values are essential elements of the control environment. They affect the design, administration, and monitoring of other components of IC. An entity's ethical and behavioural standards and the manner in which it communicates and re-in-forces them, determine the entity's integrity and ethical bahaviour. In spite of the IC system established in entities, there are always discrepancies, limitations, and deficits, when it comes to implementation [6]. The introductions of IC systems in many organisations in Ghana have had many benefits. Among them, are assisting management to ensure that policies are adhered to, proper decision is taken to ensure the achievement of the organisation's objectives and safeguard the various assets of the company? As a result of the benefits that would be derived from establishing internal controls, organizations' management establishes IC system to ensure that policies are adhered to, and that proper decision is taken by the right person. This is also done in order to ensure University objectives are achieved.

However, the extent to which the system operates, and whether it is effective and efficient depends largely on the kind of caliber of personnel. Interestingly, no matter how elaborate an organisation's internal control systems are designed or established, it cannot be a guarantee against efficiency and effectiveness of operations. A good internal control system cannot be a proof against fraudulent activities collusions, especially, on the part of those holding position of trust. Moreover, internal control systems which depend largely on segregation of duties can be flawed or relaxed through collusion, while persons in whom authority is vested can also avoid controls. [7] Besides, management in position of trust could also override these controls, which it is expected to administer. Therefore, in order to know the extent to which the system operates, and as to whether it is effectively and efficiently operated, there is the need to evaluate the system.

However, in view of this, the researchers studied and investigated how the caliber of personnel Influence of Management's Compliance to internal controls at the Organizational and Institutional levels impacted the attitudes of employees to make them more productive and effective. Also characterized and analyzed data results which was put in place as a proper means of internal control system which, if performed at the right time, frequently and purposefully, will help to identify the effectiveness of the staff and the lapses that need to be addressed.

\section{Methodology}

Research methodology defines the systematic and scientific procedure used to arrive at the results and findings for a study against which claims for knowledge are evaluated. [8] Against this background, it was found that the descriptive research survey design was appropriate and used for the study because it enables researchers to administer a set of questions to a large number of respondents concerning the current status of the issue under study. Furthermore, this study had "learning by participation" as its main objective. It implies that, the researchers and individuals identifies a problem; finding the courses and recommendation, advice for an intervention mechanism to solve that problem. The purpose of this study that necessitated the choice of research to enhance management's compliance to internal control assessment procedures at the institutional and organizational levels. When the procedures involved in the use of research method were thoroughly examined, it fitted the topic for this study, hence its adoption. In order to solicit information from staff of the organization, the basic instruments used were interview and questionnaire. On the collection of data, a semi-structured interview schedule was arranged with the staff members, during which a lot of information were gathered to get information on review issues that were pertaining within the establishment. A questionnaire was used to further solicit the causes of gaps within the assessment system. The research questions were the basis on which all the data gathered for the study were characterised and analysed. The data analysis was done with the aid of the descriptive statistics approach emphasising mainly on the percentage (\%) technique. Other data from the interviews were analysed with the view of Ornamental management's compliance 
to review procedures.

\subsection{Results and Discussion}

\subsection{Results}

\subsubsection{Employees detail}

From figure 1, breakdown of total number of respondents selected in the institution, taking into consideration the sex internal control units in the various job categories.

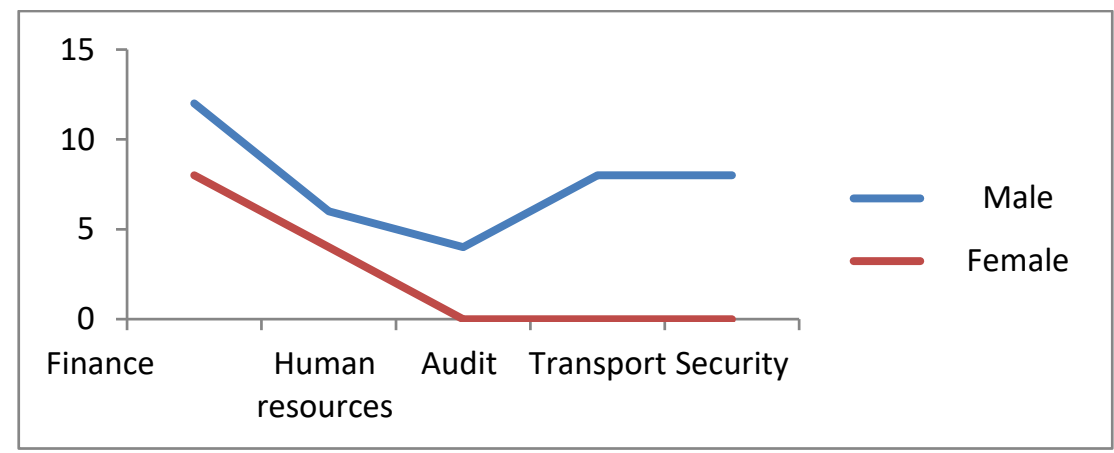

Figure 1 Breakdown of number of respondents Selected

Five categories of respondents were dealt with. This comprises finance personnel, human resources personnel, audit personnel, transport personnel, and security personnel. Twenty (20) finance personnel comprising twelve (12) males and eight (8) females were selected. At the human resources unit six (6) males and four (4) females were selected. At the audit unit four (4) males were selected. Also eight (8) males were selected from the transport and finally, eight males were selected from security unit. This summed up the respondents to a total of fifty (50).

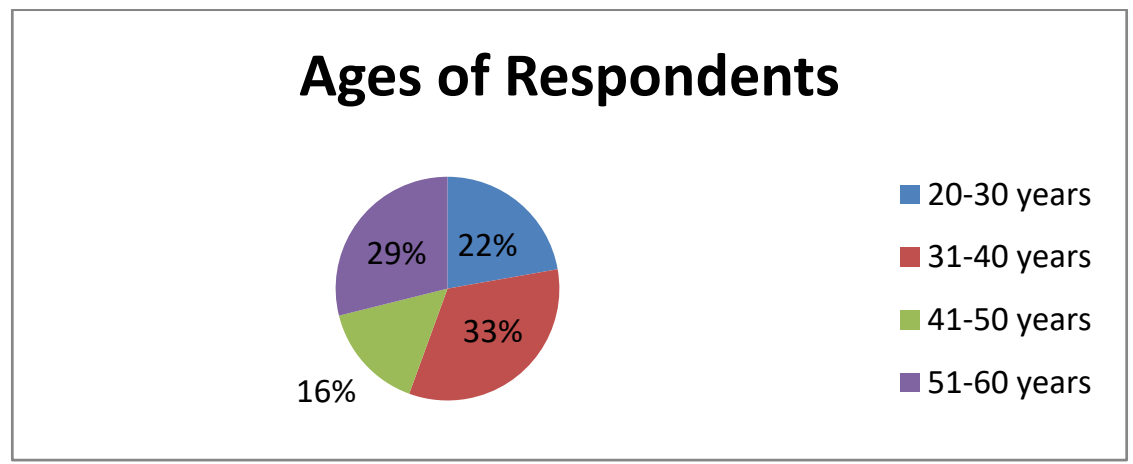

Figure 2 Background of the respondents

The results indicates that about $22 \%$ of the respondents are between the ages of 20 and 30 years with $33 \%$ between the ages of 31 and 40 years, and 16\% between 41 years and 50 years whiles $29 \%$ are ranging from 51 years to 60 years. The study observed that the elderly that is those between the ages of thirty one (31) years to sixty (60) years in the University, adhere to the control system more that the younger ones, that is those of ages twenty (20) to thirty (30). 


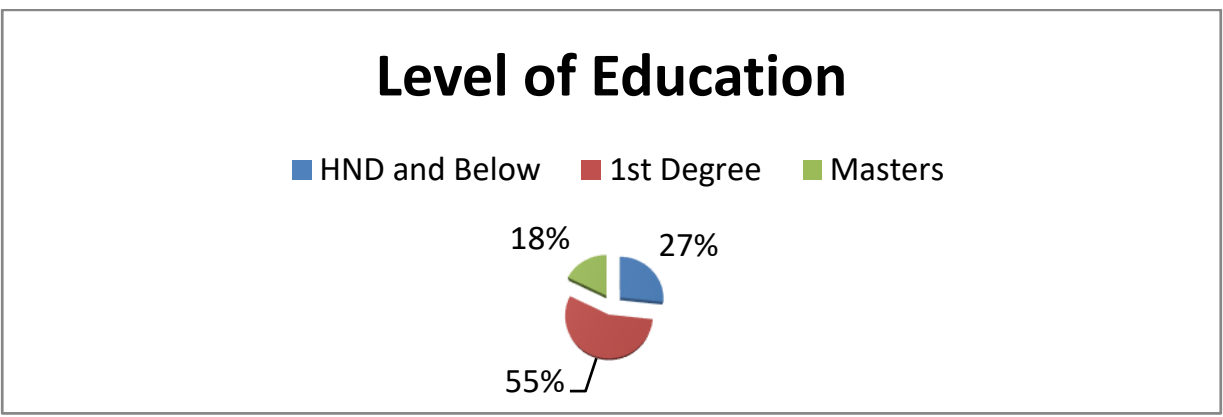

Figure 3 Respondents Levels of Education

Figure 3 reveals that $27 \%$ of the respondents are HND holders and certificates below that 55\% holds first degree, and $18 \%$ of them have master's degree. The study revealed that those with higher levels of education in the University know more about internal controls and as such the need to adhere to the control system established in the University. This is because the get the opportunity to attend seminars and workshops since internal controls are important to good corporate governance, issues on the systems are raised and they learn from that. The lower certificate holders with fewer responsibilities have little knowledge on the controls but also adhere to the controls because their activities are guided by those in authority.

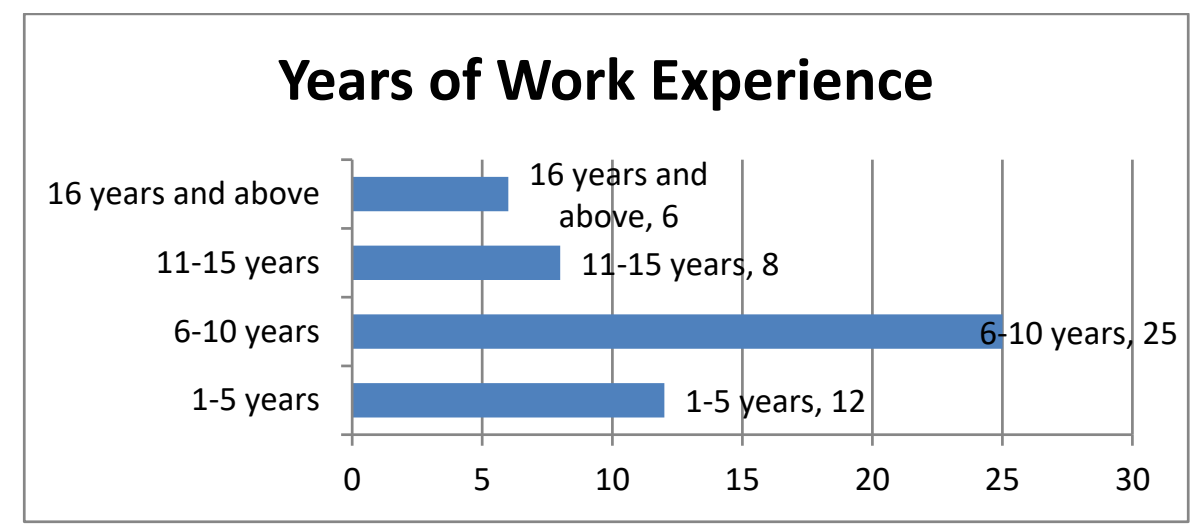

Figure 4 Years of Experience of Respondents

From Figure 5 it is revealed that 23\% of the respondents have worked with the College for up to five (5) years, $49 \%$ have worked for about six (6) to ten (10) years, and 16\% of them have been working there for the past eleven (11) to fifteen (15) years, whiles $12 \%$ have worked for more than sixteen (16) years at the College. From the study, it was observed that more experienced people in the University who understand the control system very well try to find their way out. That is they try to some extent to outwit the system to their favour while the in experienced staff who may not know more about the procedures only do what they are asked to do, as such go astray from the appropriate policies.

Figure 5 describes the total number of respondents for the various categories of job with their percentages. 


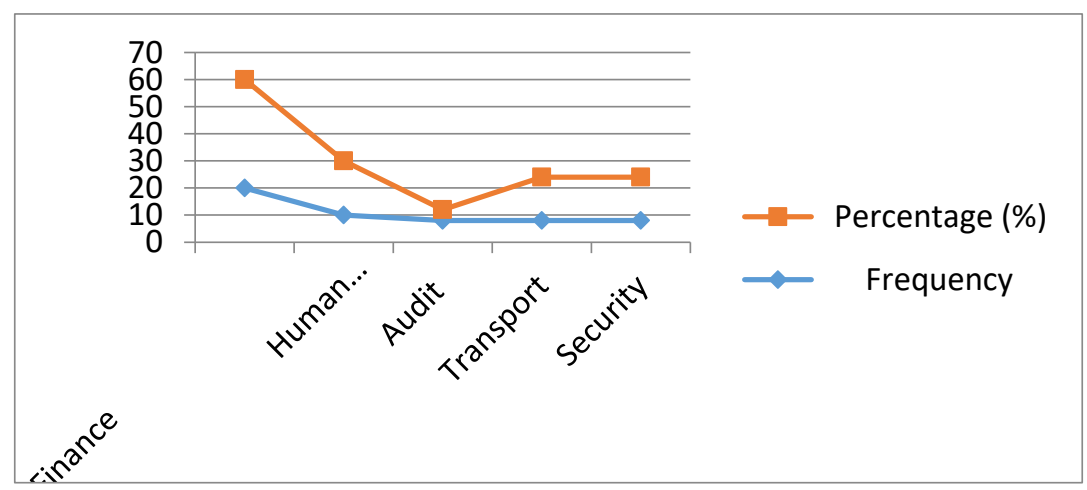

Figure 5 Respondents selected from the various categories of job

Twenty (20) respondents were selected from Finance representing $40 \%$ of the total respondents. Ten (10) were selected from Human Resource Section, representing $20 \%$ of the total respondents, four (4) from Audit unit also representing $8 \%$ of the total respondents, eight (8) respondents were also selected from the Transport Section representing $16 \%$ of the total respondents, and finally eight (8) respondents also representing $16 \%$ of the total responses, were selected from Security Unit.

\subsubsection{Use of Assets in the Institution}

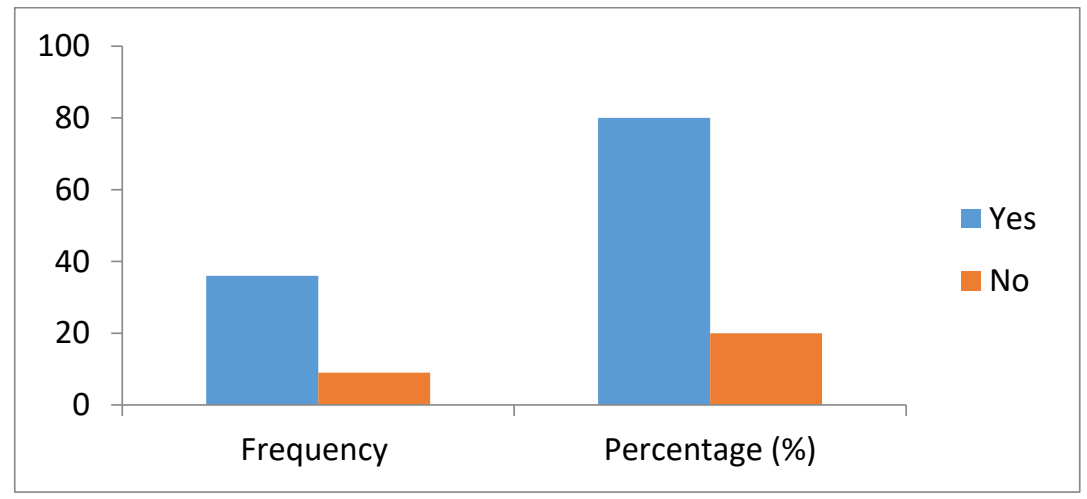

Figure 6 are assets handing and management stipulated.

From figure 7, Thirty-six (36) respondents representing $80 \%$ of the total responses responded "Yes" as to whether asset handling and management are stipulated in a document. Nine (9) respondents, representing $20 \%$ of the responses, however, responded "No". Therefore, taking the views of the majority to be the general view, it could be said that assets handling and management in the University is stipulated in a document. However, this gives the total response to either in the positive or the negative to the question as to whether there could be unauthorised use of assets in the Institution. 


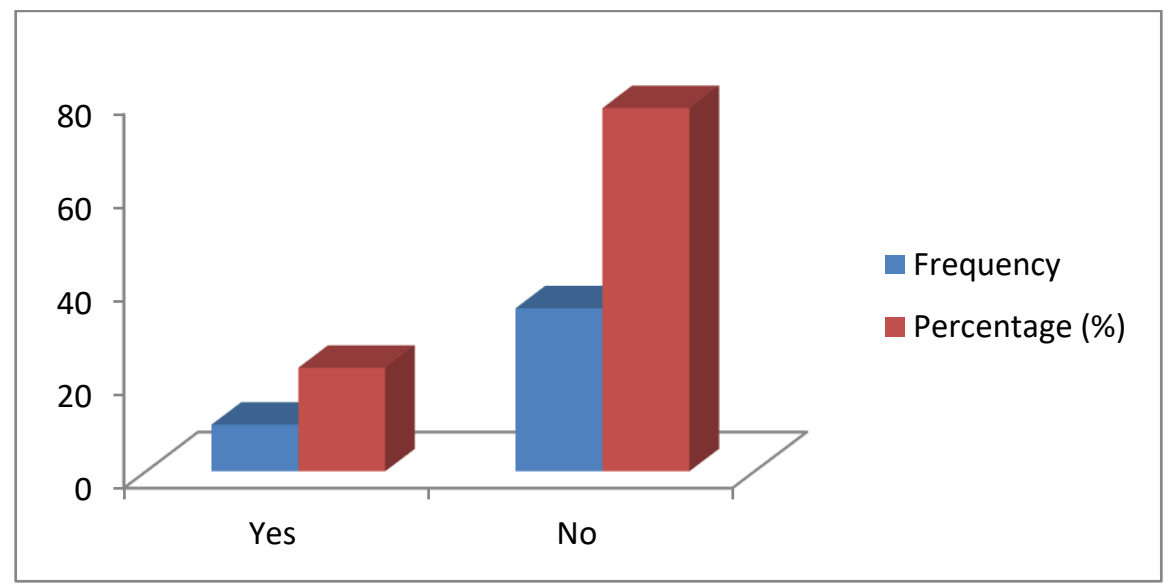

Figure 7 Can there be unauthorised and unapproved use of assets

Again, a total of ten (10) respondents answered "yes" to unauthorised and unapproved use of assets. This represents $22.22 \%$ of the responses. On the other hand, thirty-five (35) respondents, representing $77.78 \%$ of the total responses answered "no". To them, an asset cannot be used without an approval given to do so. Considering the views of the majority, unauthorized use of assets is not allowed in the Institution.

Figure 8 gives the respondents to the question whether movement of assets in the Institution are recorded.

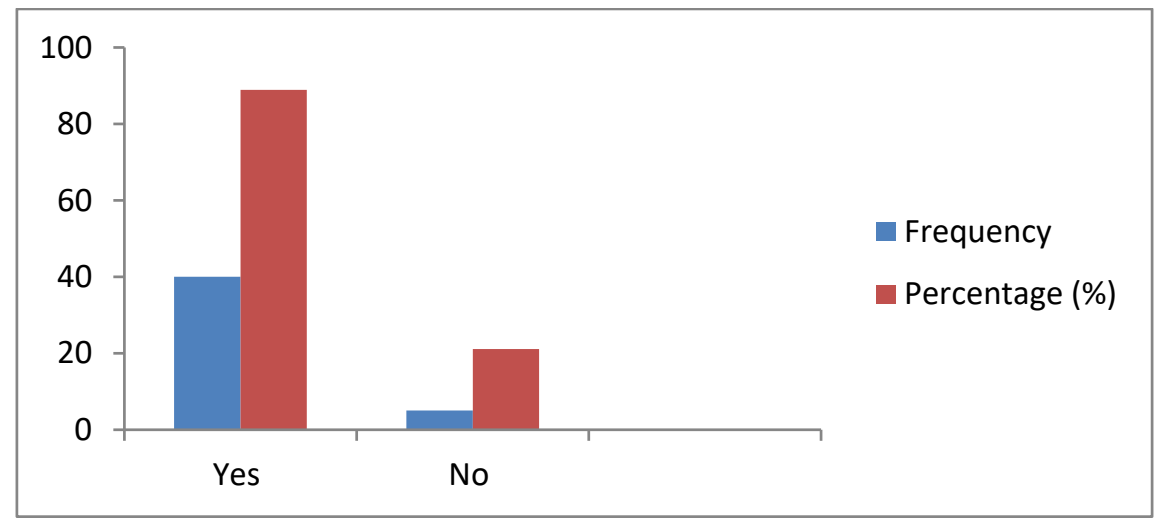

Figure 8 Are movements of assets recorded

From figure 8 again, forty (40) respondents, representing $88.89 \%$ of the total responses responded "yes". Meaning movement of assets in the Institution are recorded so that at any point in time any movable assets could be located or traced. Five (5) of the respondents representing $21.11 \%$ of the responses responded to the contrary.

Figure 9 gives respondents views as to whether there are proper physical safeguards and facilities to protect cash and other assets. 


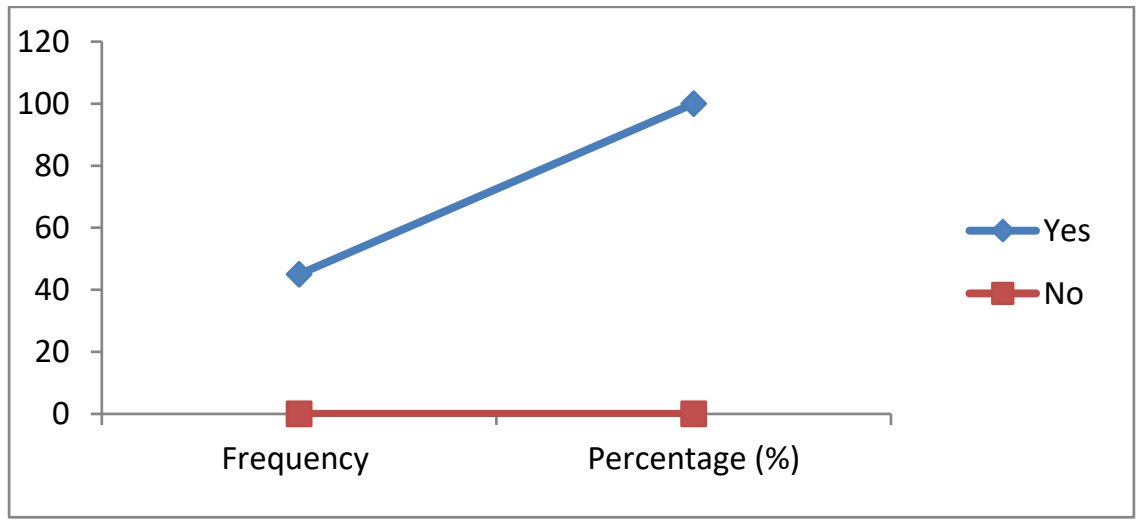

Figure 9, Are there proper physical safeguards and facilities to protect cash and other assets

The study revealed that cash and other assets of the Institutions are being protected by proper physical safeguards and facilities. This was made known as all the forty-five (45) respondents representing $100 \%$ of the total responses answered "yes" to the question that was put forward to them, as there wasn't any "No" answer to the question.

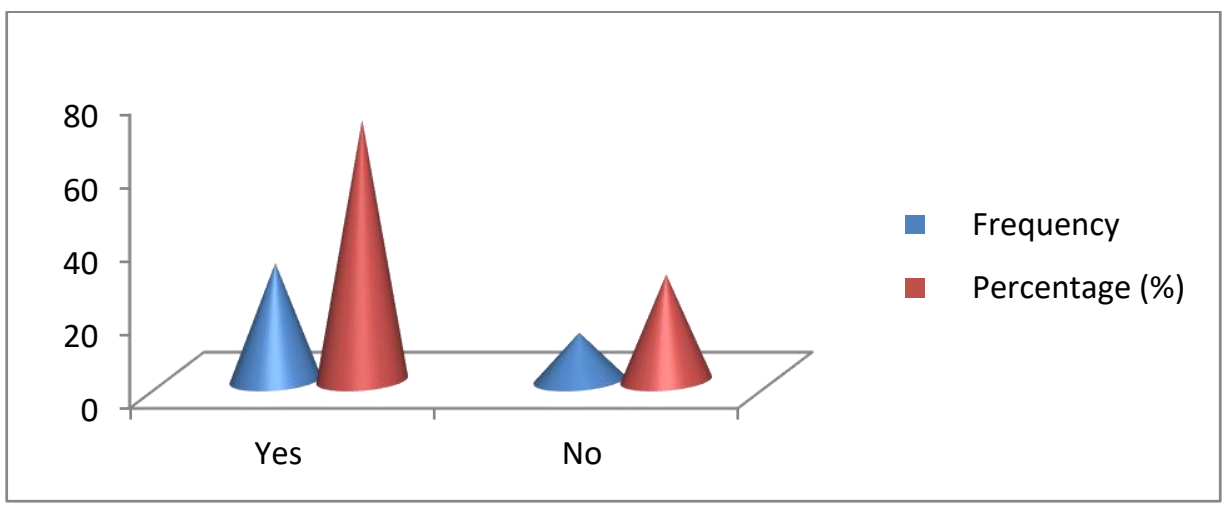

Figure 10, Are assets applied only in the service of the institution.

Responses presented by figure 10 on whether assets are applied only in the service of the University was that out of the forty five (45) respondents, thirty-two (35) of them, which represent $71.12 \%$ of the responses responded 'yes'. The remaining thirteen (13), representing $28.88 \%$ of the total responses gave negative responses. From the various responses given by the respondents on the question put forward to them to ascertain whether measures are put on the use of the institutional assets, it was realized from the responses, by considering the majority views to be the general views of respondents, that effective measures are put on the use of the University's assets.

\subsubsection{Caliber of Personnel Employed to Improve upon Internal Control System}

Responses from respondents on the characteristics of personnel employed in the Institutions to help improve upon the internal control system are presented in figure 11. 


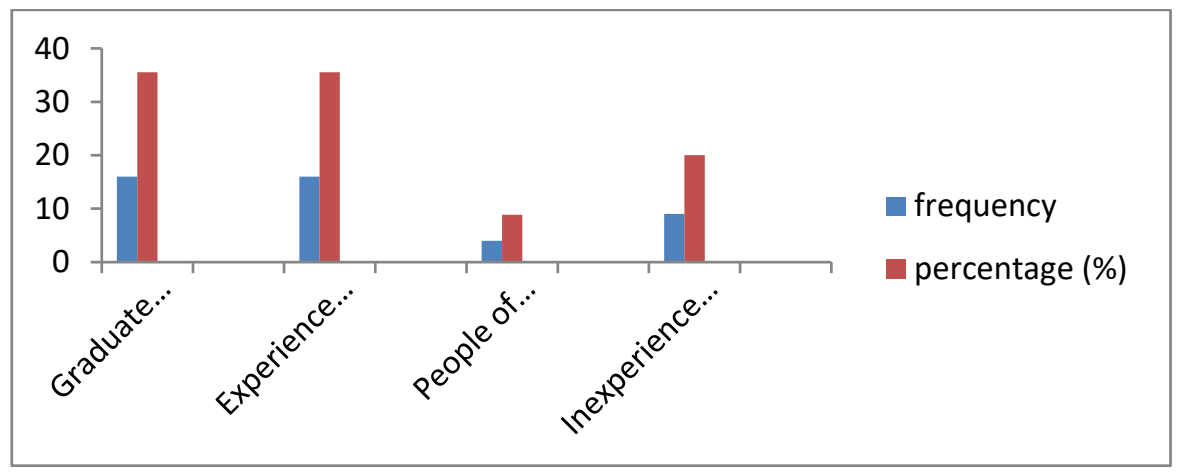

Figure 11.Calibre of personnel employed in the University

From figure 11, sixteen (16) respondents which represent $35.56 \%$ of the total respondents said that employed are degree holders. Another sixteen of the respondents, which also represents $35.56 \%$ of the responses, said personnel being employed are experienced. Four (4) respondents also representing $8.88 \%$ of the responses said personnel with good ethical values are those being employed in the University. Nine (9) respondents, representing $20 \%$ of the responses said that there are situations where inexperience people are also being employed. However, they said that in such a situation, such people are given some kind of training that would help equip them under-take their jobs as required from them.

From the responses presented by figures 6 to 10, it was found that internal control system at institutions and organizations, with respect to measures put in place on the use of assets, were appropriate. However, there were a few lapses, which could not be inevitable but limited. The reasons being that the system, though in place, cannot operate by itself and therefore need to be effected by people. As a result these people due to human errors, fraud or malfeasance, can manipulate the system for personal gain and bring it to shambles, which the author wish otherwise.

\subsection{Discussion}

Measures are put on the use of assets to ensure that access to assets, either directly or indirectly, are regulated and also serve as security devices and measures for the safe keeping of the assets. This is to ensure that no one has uncontrolled access to an entity's assets and to use it for his or her own interest.

According to the key components of internal control from "In Bottom-Line" [9], anyone who has access to company assets would want to misuse them, and that there is the need for effective internal control system to safeguard company assets.

In relation to this, the responses given by respondents, with respect to research question one, majority of the respondents, whose view were taken to be the general views, stated clearly that effective measures are put on the use of the institutional assets to ensure that they are judiciously used and applied in the service of the institution, which in turn helps to safeguard the organization assets and also contributes to the achievement of the institutions' objectives and goal's.

According to the report from [10] role of internal control in the public sector: A case study of Edweso government hospital, responses well to the graph in figure 6 which revealed that assets handing and management were stipulated in a document, stating clearly and firmly how the institutions expects its assets to be handled and managed. Confirmation was made from the thirty-six (36) out of the total of forty-five (45) respondents, which represents $80 \%$ of the responses from figure 6 , respectively.

From figure 7,77.78\% of the respondents which was majority views stated that assets of the University could not be made use of without first being authorized or approved to be used. They further explained that before anyone could have a use of the University's assets for the execution of business in the interest of the institution, there must be someone in authority to approve that, 
and that no one was allowed to use the organization assets for personal benefit. $88.89 \%$ of the respondents said that before any asset would be allowed to be moved, it must first be recorded so as to ensure that its movement is monitored. These were the responses given by respondents from figure 8 . In figure 9 all the respondents, representing $100 \%$ of the total responses agreed that there were proper physical safeguards and facilities to protect cash and other assets. That is cash is locked in cash safes, data on computers protected by passwords, vehicles packed and locked at the institutions premises and watched over by security personnel, etc. It was also found from $71.12 \%$ of the respondents in figure 10 that assets of the internal control units are applied in the service of the institution. The various responses from respondents with respect to research question one and interview conducted revealed clearly some of the measure put on the use of assets at Institution which are being adhered to, and as a result has helped in the effective and efficient operations towards the achievement of the Institution. As noted from the literature, internal control is only as effective as the integrity and competence of the people who develop, administer, and monitor the controls. Respondents' responses on the characteristics of personnel employed at Institutions revealed that both experienced and inexperienced people could be employed by the organization to take up operating activities. It was also found that most of the operating staff are not highly qualified people and in addition the ethical values of personnel are mostly not taken into account during employment. In view of this there seems to be influences of the caliber of personnel and internal control system of the Institutions.

\section{Conclusion}

Internal control systems has been the subject of a series of explorations since generations, however, some originally in both government and private sector legislators and regulators gave internal control significant attention as a result of Watergate relation of illegal domestic political contributions. The study sought to enhance and investigated the caliber of personnel Influence of Management's Compliance to internal control at the Organizations and Institutions levels. There was a critical characteristics and analysis that revealed the following as pertaining in an organisation;

1. The work output is not encouraging.

2. The study revealed the actual establishment of internal control system prevailing at institutional and organizational levels, which has contributed, to a large extent, the achievement of the organization objective.

3. Various constituents of internal control systems in the institutions, all possible strategies and mechanism that are in place and those needed to be implemented to make the institutional internal control system more effective and efficient, were unearthed and addressed accordingly to help improve upon the system.

4. Management area, involving their subordinates, has a lesser attention pull-out and internal control systems are not motivating to work well.

\section{References}

[1] Babalola J. B. (ed. 2003). Basic text in educational planning (first edition). Ibadan: Department of Educational Management, University of Ibadan. Pp. 255-299

[2] Kumuthinidevi, S. (2016). A study on effectiveness of the internal control system in the private banks of Trincomalee. International journal of scientific and research publications, 6(6)600-612.

[3] Ohiokha, F. I. and Akhalumeh, P.B. (2013). Auditing standards and auditors' performance: The Nigerian experience. European journal of accounting auditing and finance research 1

(1) $29-35$

This publication is licensed under Creative Commons Attribution CC BY. 
[4] Kugler, M. and Rosenthal, H. (2000). Checks and balances: An assessment of the institutional separation of political powers in Colombia. Discussion papers in economics and econometrics. Southampton: University of Southampton. Available online at http://www/soton.ac.uk/ econweb/dp/dp00.html Retrieved on 15 February, 2020

[5] Gbenro, Abisola. A and Babalola, J. B. (2015). A tracking survey of resource flow from UBEC to public primary schools in Ibadan North Local Government Area of Oyo State, Nigeria. (J) International journal of research in education methodology, 7(1):1048-1060

[6] Mammoria, C.B.; Mammoria, Satish and Gankar, C.V. (1999). Dynamics of industrial relations, Delhi: Himalaya Publishing House, Delhi, p. 462 available online at https://shodhganga.inflibnet.ac.in/bitstream/10603/112972/10/10_chapter\%202.pdf

[7] Computer Assisted Analysis Techniques and Solutions, CAATS (2019). The death of continuous auditing. Available online at https://caats.ca/2019/02/06/the-death-of-continuous-auditing/

[8] Aboagye K. I., Baidoo P. and Mensah O. P., (2020) The Influence of Management's Compliance to Appraisal Procedures at the Organizations and Institutions, American Journal of Operations Management and Information Systems. Vol. 5, No. 2, pp. 20-24. doi: $\underline{10.11648 / \text { j.ajomis.20200502.11 }}$

[9] Cerini, K. (2016). “Key components of internal controls”. In Bottom-line. 13:1. Available at: https://ceriniandassociates.com/wpcontent/uploads/2016/12/Bottom-Line-Vol-13.pdf

Retrieved 12 February 2020

[10] Boakye, E. O. (2016). The role of internal control in the public sector: A case study of Edweso government hospital. Uploaded to Research gate on 03 August 2016. Available at https://www.researchgate.net/publication/305807436 